\title{
QUALIDADE DA BIOMASSA FLORESTAL COMERCIALIZADA NO VALE DO ITAJAÍ, SC
}

\author{
Jackson Roberto Eleotério ${ }^{1}$, Anderson Quintino ${ }^{2}$, Antonio Carlos Stramosk ${ }^{2}$, \\ Cláudia Mariana Kirchheim da Silva ${ }^{2}$, Rafael Kiefer ${ }^{2}$ \\ ${ }^{1}$ Universidade Regional de Blumenau, Programa de Pós-Graduação em Engenharia Florestal, Blumenau, Santa Catarina, Brasil - \\ jreleote@furb.br \\ ${ }^{2}$ Universidade Regional de Blumenau, Curso de Engenharia Florestal, Blumenau, Santa Catarina, Brasil
}

Recebido para publicação: 17/08/2015 - Aceito para publicação: 08/03/2017

\begin{abstract}
Resumo
Características tecnológicas como o alto teor de umidade e a baixa massa específica à granel afetam a competitividade da biomassa florestal e limitam a sua participação na matriz energética nacional. O objetivo deste trabalho foi determinar e comparar esses indicadores de qualidade em toretes e cavacos de Pinus sp., Eucalyptus sp. e misturas dessas e de outras espécies não identificadas. Foram coletadas 137 amostras no momento do recebimento pelas indústrias consumidoras, sendo 101 na forma de cavacos e 36 na forma de toretes. A massa específica à granel dos cavacos e o teor de umidade de Pinus sp. foram superiores aos obtidos para os cavacos de Eucalyptus sp. Apesar do maior teor de umidade, a massa específica anidra dos cavacos de Pinus sp. foi superior à dos cavacos de Eucalyptus sp. Os toretes apresentam teor de umidade significativamente superior aos cavacos apenas para Pinus sp. Os teores de umidade se aproximam dos apresentados por diversos autores como encontrados em árvores em pé ou recém abatidas, mantendo-se constantes ao longo do tempo, indicando a ausência de práticas como a secagem para melhorar a qualidade da biomassa.

Palavras-chave: Cavacos; energia da madeira; lenha; teor de umidade; massa específica.
\end{abstract}

\begin{abstract}
Quality of forest biomass sold at Vale do Itajaí, SC. Technological characteristics such as high moisture content and low bulk density affect the competitiveness of forest biomass and limit their participation in the national energy matrix. The objective of this study was to determine and compare these quality indicators in chips and firewood of Pinus sp., Eucalyptus sp. and mixtures. One hundred and thirty-seven samples were collected at the time of receipt by the consumer industries, 101 in the form of chips and 36 in the form of firewood. The bulk density of the chips and moisture content of the Pinus sp. are higher than those obtained for Eucalyptus sp. biomass. Even though the larger moisture content of Pinus sp. chips, the anhydrous specific gravity is greater than that founded for Eucalyptus sp. chips. The firewood has significantly higher moisture content than chips only for Pinus sp. The moisture content is near of found by several authors for stand or recent felled trees. Over time, this characteristic is constant, indicating the absence of practices as drying to improve the biomass quality.
\end{abstract}

Keywords: Chips, wood energy, firewood, moisture content, specific gravity.

\section{INTRODUÇÃO}

O Brasil se destaca no uso de fontes renováveis de energia, que representam $41 \%$ da matriz energética nacional, contra apenas $8,1 \%$ nos países da Organização para a Cooperação e Desenvolvimento Econômico (OCDE). A lenha e o carvão vegetal foram responsáveis, em 2013, pela oferta de 24,6 Mtep, valor que representa $8,3 \%$ do total, entretanto $4,3 \%$ menor que o registrado em 2012. No setor industrial a lenha representa $8,7 \%$ do consumo de energia; especificamente $6,5 \%$ na indústria têxtil, $9,7 \%$ na indústria de alimentos e bebidas, $15,3 \%$ na indústria de celulose e papel e 51,9\% na indústria cerâmica (EMPRESA DE PESQUISA ENERGÉTICA - EPE, 2014).

Ainda que a situação seja aparentemente confortável com relação à dependência de fontes renováveis, a oferta e o consumo de energia de fontes não-renováveis como o gás natural e os derivados de petróleo tem aumentado no Brasil a taxas muito maiores que as observadas para a biomassa (EPE, 2014). Os investimentos em infraestrutura e pesquisa têm prezado por fontes fósseis, combustíveis da economia de alto carbono. Apesar do potencial para participar com uma fração maior na matriz energética nacional, substituindo parcialmente o uso de combustíveis fósseis, alguns aspectos tecnológicos como a baixa densidade energética e aspectos relacionados com a eficiência da combustão limitam a adoção da lenha como fonte energética por inúmeras indústrias.

FLORESTA, Curitiba, PR, v. 47, n. 2, p. 213 - 220, abr. / jun. 2017.

Eleotério, J. R. et al.

ISSN eletrônico 1982-4688

DOI: $10.5380 /$ rf.v47i1.42655 
O uso das informações tecnológicas relacionadas à conversão energética da biomassa, como poder calorífico, massa específica e demanda de ar, é condição essencial para que essa alternativa energética seja considerada como uma opção viável. O poder calorífico da madeira anidra está relacionado com a sua composição elementar, sendo observadas pequenas, mas significativas, variações entre espécies. Costumeiramente os maiores valores são encontrados na madeira de coníferas (BRAND et al., 2014, BRAND et al., 2011, SPINELLI et al., 2011, SENELWA; SIMS, 1999). Outro fator que pode afetar a qualidade da biomassa é a porcentagem de casca. Em alguns casos são registrados valores do poder calorífico da casca menores que os da madeira, como em Eucalyptus saligna, Eucalyptus nitens e Eucalyptus globulus (SENELWA; SIMS, 1999), entretanto, em outros casos não são observadas diferenças significativas como em Pinus radiata (SENELWA; SIMS, 1999) e em coníferas (SPINELLI et al., 2011).

Indubitavelmente o fator determinante para a qualidade da biomassa florestal é o teor de umidade; não apenas pelo seu impacto no poder calorífico, mas também pelo seu impacto nos custos de transporte e armazenagem. Sosa et al. (2015) utilizaram esta variável como fator determinante em uma cadeia de suprimento otimizada na Irlanda e a redução no teor de umidade permitiu aumentar a distância em que o abastecimento da biomassa se tornasse competitivo.

A redução no poder calorífico com o aumento do teor de umidade em base úmida apresenta uma relação linear, com coeficiente de $-0,1335 \mathrm{~kJ} /(\mathrm{kg} \%)$ para Pinus radiata e de $-0,1391 \mathrm{~kJ} /(\mathrm{kg} \%)$ para Eucalyptus nitens (SENELWA; SIMS, 1999). Esse impacto negativo no poder calorífico justifica a busca de estratégias para redução do teor de umidade, seja pela seleção de material com menor teor de umidade inicial, pela remoção de casca, pela secagem ao ar em ambiente coberto ou não e mesmo pela secagem artificial.

A época do ano impacta significativamente no teor de umidade inicial em Pinus taeda e Eucalyptus dunnii (BRAND et al., 2012). Além desse fator, a idade e o índice de sítio ainda são outros fatores que afetam o teor de umidade inicial. A madeira obtida de povoamentos mais velhos e daqueles cultivados em sítios com índices menores apresentaram madeira de maior massa específica e menor teor de umidade inicial (BAKER et al., 2012). Brand et al. (2011; 2014) não encontraram diferenças no teor de umidade inicial de toras de Pinus taeda e de Eucalyptus dunnii.

Como é impraticável colher as florestas exclusivamente para biomassa e apenas no período de menor teor de umidade inicial, essa variação deve ser considerada nas diferentes estratégias de secagem. A secagem ao ar é uma das estratégias mais utilizadas para melhorar a qualidade da biomassa, podendo resultar em ganhos de até $49 \%$ no poder calorífico líquido para Pinus taeda e de até $59 \%$ para Eucalyptus dunnii após quatro meses de secagem (BRAND et al., 2011).

A estocagem da madeira é considerada por Brand et al. (2014) como um tratamento que contribui significativamente para o aumento da qualidade da biomassa. Na realidade é a redução no teor de umidade e não a estocagem ou armazenamento que causa este efeito. A simples estocagem em condições inadequadas apenas aumenta o custo e não a disponibilidade líquida de energia. Pasila (2013) afirma que o maior desafio no uso da madeira para energia é o tempo de estocagem para a redução do teor de umidade. Röser et al. (2011) afirmaram que a secagem ao ar é um método efetivo e viável para a redução do teor de umidade da madeira para energia na Europa.

A temperatura do ar é apontada como o fator ambiental de maior influência na secagem ao ar de cavacos de Populus spp. (PARI et al., 2013); já a umidade relativa e a precipitação atmosférica não apresentaram efeito significativo. Contudo, para a secagem de Pinus sylvestris a umidade relativa do ar foi o fator ambiental de maior efeito, incorporado junto com a temperatura e a precipitação em um modelo empírico para estimar a variação diária no teor de umidade (ERBER, 2012).

A remoção da casca influencia significativamente a taxa de secagem (RÖSER et al., 2011). O impacto do aumento da área de transferência de massa, da redução do comprimento característico no sentido do fluxo de água e a remoção de uma barreira semipermeável, que é a casca, são indicados por Defo e Brunette (2006) como os fatores que determinam o aumento da taxa de secagem em até três vezes. Esses últimos autores modelaram a secagem utilizando o potencial químico como força motriz e apresentaram perfis de umidade para toras com e sem casca de diferentes diâmetros.

A casca de diferentes espécies deve ter permeabilidade e difusividade distintas, o que pode explicar o fato registrado por Brand et al. (2011), da madeira de Pinus taeda na forma de toras com casca secar a uma taxa significativamente menor que a madeira de Eucalyptus dunnii nessa mesma forma. $\mathrm{O}$ efeito da casca e da fragmentação da madeira também foi observado por Brand et al. (2014) que encontraram taxas de secagem superiores para costaneiras que para madeira em tora de Pinus taeda. A exposição da madeira também contribuiu para o maior re-umedecimento após períodos chuvosos. Nesse sentido, de expor uma área maior de madeira para a transferência de massa, as rachaduras de topo e superficiais são apontadas como benéficas à secagem (DEFO; BRUNETTE, 2006).

Estudando o efeito da cobertura das pilhas de toras com filmes plásticos, Visser et al. (2014) encontraram, no verão, taxas de secagem menores para as pilhas cobertas e não encontraram efeito significativo 
da cobertura no inverno. Röser et al. (2011) afirmaram que o efeito da cobertura variou segundo o país considerado, sendo recomendado na Escócia e Finlândia e não na Itália.

A complexidade da secagem ao ar, influenciada por diversos fatores da madeira e do ambiente, tem justificado a pesquisa de condições ideais de secagem artificial. $\mathrm{O}$ efeito da temperatura, de 40 a $80{ }^{\circ} \mathrm{C}$ foi avaliado por Phanphanich e Mani (2009), que ajustaram modelos empíricos para o teor de umidade em função do tempo. Já Pang e Xu (2010) apresentaram um modelo fenomenológico e os resultados da simulação da secagem de cavacos em leito móvel, com e sem reversão no sentido do fluxo de ar.

Motivadas pela redução na mão-de-obra e pela disponibilidade de sistemas mecanizados de alimentação, percebeu-se nos últimos anos que muitas empresas estão substituindo o uso de toretes por cavacos como combustível de suas caldeiras. O mercado fornecedor também tem se adaptado a essa situação, convertendo grande parcela do material obtido em desbastes e resíduos florestais em cavacos, além dos resíduos obtidos durante o processo de desdobro de toras, como refilos e destopos.

Apesar da conhecida influência do teor de umidade no poder calorífico líquido, da disponibilidade de tecnologias para a redução no teor de umidade e da existência de normas que poderiam regular o mercado como a DIN EN ISO 17225-1 (DEUTSCHES INSTITUT FÜR NORMUNG, 2014), é prática comumente observada a comercialização de madeira para energia apenas por volume ou pela massa úmida.

Assim sendo, pela influência do mercado consumidor pouco exigente, acredita-se que o teor de umidade da biomassa florestal comercializada no Vale do Itajaí é próximo ao teor de umidade de árvores em pé ou recém abatidas registrado para Pinus sp. e Eucalyptus sp., independente da forma de apresentação, em cavacos ou toretes. Outra hipótese é que a massa específica anidra à granel dos cavacos de Pinus sp. é menor que a dos cavacos de Eucalyptus sp.

O objetivo deste trabalho foi avaliar e comparar o teor de umidade de toretes e cavacos e a massa específica a granel desses últimos como indicadores de qualidade da biomassa florestal utilizada por indústrias de papel, de alimentos e têxteis.

\section{MATERIAL E MÉTODOS}

\section{Locais de amostragem}

Foram coletadas 137 amostras, sendo 100 amostras em indústrias de papel, 33 amostras em indústrias têxteis e quatro amostras em indústrias de outros setores. Quanto à forma de apresentação, 36 amostras estavam na forma de toretes e 101 na forma de cavacos. No município catarinense de Apiúna foram coletadas 25 amostras, 71 amostras foram coletadas em Indaial, 31 amostras em Taió e 10 amostras em outros municípios; todos do Vale do Itajaí. Com o propósito de avaliar a variação no teor de umidade ao longo do tempo, as coletas de diferentes cargas de cavacos em uma indústria de papel de Indaial (SC) e em uma indústria têxtil de Apiúna (SC) foram distribuídas em um período de três meses.

\section{Variáveis consideradas}

Cada amostra foi constituída de, no mínimo, $2 \mathrm{~kg}$ de massa úmida, coletada no momento do recebimento pelas indústrias consumidoras. No caso dos toretes, a seção removida era equidistante dos topos. Imediatamente após a coleta as amostras foram acondicionadas em embalagens plásticas até o momento das pesagens.

O teor de umidade, em base úmida, foi determinado pelo método gravimétrico, segundo a norma ASTM D4442-07 (ASTM, 2007). A massa específica aparente a granel dos cavacos foi determinada como sendo a razão entre a massa úmida e o volume do recipiente padrão, de $5 \mathrm{dm}^{3}$. A massa específica anidra à granel foi determinada como sendo a relação entre a massa seca de cavacos em relação ao volume do recipiente padrão, de $5 \mathrm{dm}^{3}$. A biomassa foi classificada de acordo com as classes apresentadas na norma DIN EN ISO 17.225-1 (DEUTSCHES INSTITUT FÜR NORMUNG, 2014).

A partir da análise macroscópica os cavacos foram classificados em Pinus sp. Eucalyptus sp. e misturas de madeiras desses e de outros gêneros, respectivamente às classes 1.2.1.2, 1.2.1.1 e 1.2.3 da norma DIN EN ISO 17.225-1 (DEUTSCHES INSTITUT FÜR NORMUNG, 2014).

\section{Análise estatística}

A análise estatística iniciou pelo teste de homocedasticidade de variância de Bartlett, com $\alpha=5 \%$. Em caso de rejeição da hipótese nula, os valores foram transformados segundo a equação abaixo proposta por Manly (1976).

$$
y_{i}^{(\lambda)}=\frac{e^{y_{i} \lambda}-1}{\lambda}
$$

em que: $y_{i}^{(\lambda)}$ a variável transformada; $y_{i}$ a variável observada e $\lambda=$ fator de correção.

FLORESTA, Curitiba, PR, v. 47, n. 2, p. 213 - 220, abr. / jun. 2017.

Eleotério, J. R. et al.

ISSN eletrônico 1982-4688

DOI: $10.5380 /$ rf.v47i1.42655 
A normalidade dos resíduos foi avaliada pelo teste de Lilliefors $(\alpha=5 \%)$, na condição transformada quando pertinente. Atendidos os pressupostos da análise de variância, as médias foram comparadas pelo teste de Tukey com $\alpha=5 \%$.

A estabilidade do teor de umidade ao longo do tempo foi avaliada por meio de gráficos de controle, sendo cada determinação do teor de umidade considerada uma medida individual e os limites de controle determinados segundo a equação abaixo (MONTGOMERY, 2009). Esses limites de controle definem os valores máximos e mínimos esperados se a característica considerada se mantiver estável.

$$
\mathrm{LC}=\overline{\mathrm{X}} \pm 3 \frac{\mathrm{MR}}{\mathrm{d}_{2}}
$$

em que $\overline{\mathrm{X}}$ teor de umidade médio, MR amplitude média entre duas amostras consecutivas e $\mathrm{d}_{2}$ fator que relaciona a amplitude da amostra ao desvio padrão populacional.

\section{RESULTADOS E DISCUSSÃO}

\section{Teor de umidade}

A tabela 1 apresenta os valores do teor de umidade estratificados por espécie e forma de apresentação do material. O teor de umidade apresentou, pelo teste de Bartlett, heterocedasticidade de variâncias, situação que foi revertida com a transformação de dados, utilizando $\lambda=0,05$ na equação 1 . Após a transformação os resíduos apresentaram distribuição normal pelo teste de Lilliefors.

Tabela 1. Número de amostras $(\mathrm{N})$ e teor de umidade base úmida (U\%) por espécie e por forma de apresentação do material.

Table 1. Number of specimens $(\mathrm{N})$ and moisture content $(\mathrm{U} \%)$ by species and way of presentation of the material.

\begin{tabular}{|c|c|c|c|c|c|c|}
\hline \multirow{2}{*}{ Espécie } & \multicolumn{2}{|c|}{ Cavaco } & \multicolumn{2}{|c|}{ Torete } & \multicolumn{2}{|c|}{ Média } \\
\hline & $\mathbf{N}$ & $\mathrm{U}(\%)$ & $\mathbf{N}$ & $\mathrm{U}(\%)$ & $\mathbf{N}$ & $\mathrm{U}(\%)$ \\
\hline Eucalyptus sp. & 44 & $46,9^{\mathrm{aA}}(7,3)$ & 20 & $44,7^{\mathrm{aA}}(7,8)$ & 64 & $46,3^{\mathrm{A}}(7,4)$ \\
\hline Mistura & 22 & $47,2^{\mathrm{A}}(5,3)$ & - & - & 22 & $47,2^{\mathrm{A}}(5,3)$ \\
\hline Pinus sp. & 35 & $51,7^{\mathrm{aB}}(6,1)$ & 16 & $65,4^{\mathrm{bB}}(1,9)$ & 51 & $56,0^{\mathrm{B}}(8,2)$ \\
\hline Média & 101 & $48,6^{\mathrm{a}}(6,8)$ & 36 & $53,9^{\mathrm{b}}(11,9)$ & 137 & $50,0(8,7)$ \\
\hline
\end{tabular}

Médias seguidas por mesmas letras minúsculas na mesma linha e maiúsculas na mesma coluna não diferem estatisticamente pelo teste de Tukey $(\alpha=5 \%)$. Valores entre parênteses indicam o desvio padrão.

Adotando as classes da norma DIN EN ISO 17225-1 (DEUTSCHES INSTITUT FÜR NORMUNG, 2014), o torete de Pinus sp. fica na classe M55+, a maior que pode ser declarada. Em seguida podem-se classificar na classe M55 os cavacos de Pinus sp., na classe M50 os cavacos de Eucalyptus sp. e mistura e, por fim, na classe M45 os toretes de Eucalyptus sp. Sendo o teor de umidade um indicador de qualidade, a adequação da biomassa cresce na ordem apresentada.

O teor de umidade dos cavacos de Pinus sp. é próximo ao apresentado por Furtado et al. (2012), de $54 \%$. Já o teor de umidade dos toretes é próximo ao apresentado por Brand et al. (2014) para a copa das árvores desbastadas com 10 e 12 anos, de 62 a 64\% e próximo ao valor observado por Brand et al. (2012) para Pinus taeda colhido no início do inverno, de 65\%, mas superior ao valor apresentado por Baker et al. (2012) para árvores inteiras com 8 a 17 anos da mesma espécie, de 52,3\%. O menor teor de umidade, encontrado nos cavacos, pode estar relacionado com a origem da madeira, de costaneiras da tora, com maior massa específica que a madeira de desbastes e de ponteiras, comercializada como toretes. A relação inversa entre o teor de umidade inicial e a massa específica é apresentada para diversas espécies (MUÑOZ; MOYA, 2008, TENORIO et al., 2014, HASELEIN et al., 2004). Para costaneiras, o teor de umidade de 54\% foi encontrado por Brand et al., (2014), valor próximo ao encontrado neste trabalho para os cavacos. Outra hipótese é que os cavacos, pela maior exposição às trocas de calor e massa com o ar circundante, perdem parte da massa pela evaporação da água desde conversão em cavaco até a entrega na empresa consumidora.

Os teores de umidade de cavacos e toretes de Eucalyptus sp. não diferiram significativamente entre si, apresentando valor na mesma ordem de grandeza ao apresentado por Haselein et al. (2004), de 49,9\% e Gatto et al. (2003), de 42,6\%, sendo esses valores referentes à madeira recentemente abatida, ambos em base úmida. Uma possível explicação é que a casca de Eucalyptus sp. não impede a transferência de água para o ambiente com a mesma resistência que a casca de Pinus sp., dessa forma há evaporação tanto na forma de cavacos como na forma de toretes. Taxas superiores de secagem para toretes de Eucalyptus sp. quando comparadas com as 
observadas para Pinus taeda foram registradas por Brand et al. (2012). Outra hipótese é que a baixa difusividade mássica da água na madeira de Eucalyptus sp. dificulta a saída da água, mesmo na forma de cavacos. Santos et al. (2003) caracterizam a madeira de Eucalyptus grandis como impermeável. Dessa forma, a resistência à secagem seria interna e menos dependente da área de exposição ao meio externo.

Os cavacos da mistura de espécies apresentaram teores de umidade semelhantes aos observados para os cavacos de Eucalyptus, fato que pode estar relacionado com a maior proporção de folhosas em relação às coníferas nesse material.

A biomassa de Pinus sp., seja ela na forma de toretes ou de cavacos, apresentou teor de umidade significativamente superior ao teor de umidade da biomassa de Eucalyptus sp. e da mistura. Esse fato pode estar relacionado com a menor massa específica da madeira do primeiro gênero e com taxas de secagem diferenciadas, como discutido anteriormente.

Independente da espécie e da forma de apresentação, foram observados valores de teor de umidade próximos aos encontrados em árvores em pé ou recém abatidas, como os apresentados por Baker et al. (2012) para cavacos de Pinus taeda e Pinus elliottii, por Haselein et al. (2004) para árvores de Eucalyptus grandis, por Brand et al. (2014) para toretes de Pinus sp. e de eucalipto com casca; o que demonstra que o mercado regional não está estimulando a comercialização de biomassa com menor teor de umidade. As práticas correntes de comercialização pelo volume e pela massa úmida não estimulam as práticas de secagem da biomassa, seja ao ar ou artificialmente.

\section{Massa específica dos cavacos}

A massa específica aparente dos cavacos apresentou homogeneidade de variância entre os grupos e distribuição normal dos resíduos, sem necessidade de transformação. Da mesma forma que o teor de umidade, a massa específica aparente e anidra dos cavacos de Eucalyptus sp. não diferiu da mistura (Tabela 2). Já os cavacos de Pinus sp. diferem dos cavacos de Eucalyptus sp. no que se refere à massa específica anidra e ainda aos cavacos de mistura quando se analisa a massa específica aparente.

Tabela 2. Número de amostras de cavacos $(\mathrm{N})$, massa específica aparente à granel $\left(\rho_{\mathrm{ap}}\right)$ e massa específica anidra à granel $\left(\rho_{\text {anidra }}\right)$, estratificada por espécie. Valores entre parênteses abaixo das médias são os desvios-padrão.

Table 2. Number of specimens of chips $(N)$, apparent bulk specific gravity $\left(\rho_{\text {ap }}\right)$ and anhydrous bulk specific gravity $\left(\rho_{\text {anidra }}\right)$, stratified by specie.

\begin{tabular}{cccc}
\hline Espécie & $\mathbf{N}$ & $\begin{array}{c}\rho_{\mathrm{ap}} \\
\left(\mathbf{k g} / \mathbf{m}^{3}\right)\end{array}$ & $\rho_{\text {anidra }}\left(\mathbf{k g} / \mathbf{m}^{\mathbf{3}}\right)$ \\
\hline Eucalyptus sp. & 44 & $356,1^{\mathrm{a}}(41,0)$ & $187,4^{\mathrm{a}}(22,9)$ \\
Mistura & 22 & $360,6^{\mathrm{a}}(40,0)$ & $188,8^{\mathrm{ab}}(12,7)$ \\
Pinus sp. & 35 & $414,7^{\mathrm{b}}(46,3)$ & $198,6^{\mathrm{b}}(22,0)$ \\
Média & 137 & $377,4(50,3)$ & $191,6(21,2)$ \\
\hline
\end{tabular}

Médias seguidas pela mesma letra, dentro da mesma coluna, não diferem estatisticamente pelo teste de Tukey ( $\alpha=5 \%)$. Valores entre parênteses indicam o desvio padrão.

O fato dos cavacos de Pinus sp. apresentarem massa específica anidra à granel superior à dos cavacos de Eucalyptus sp. poderia negar a hipótese que os teores de umidade desse primeiro material são maiores por causa da menor massa específica. Porém, trata-se de massa à granel e não massa da partícula, dessa forma entram em questão outros aspectos como granulometria, que alteram a acomodação do material dentro do volume considerado. Um fator que aparentemente afeta a massa específica à granel dos cavacos de Eucalyptus sp. é a casca, que apresenta menor massa específica do que a madeira e forma alongada, resultado da fragmentação diferenciada.

Apenas os cavacos de Pinus sp. podem ser classificados como BD400 segundo os critérios da DIN EN ISO 17225-1 (DEUTSCHES INSTITUT FÜR NORMUNG, 2014); os demais são classificados na classe BD350. Dessa forma e considerando a massa específica anidra à granel, a qualidade dos cavacos de Pinus sp. é melhor que a dos cavacos de Eucalyptus sp.

\section{Variação temporal do teor de umidade}

Na figura 1 é possível observar que o teor de umidade dos cavacos de Pinus sp. não extrapola os limites de controle de 36,4 e 67,0\%, indicando que a variação é o resultado de um conjunto de causas aleatórias, sem a interferência de alguma causa especial como a variação no teor de umidade inicial ao longo do ano. O mesmo ocorre para Eucalyptus sp. e a mistura (Figura 2), os limites de 26,7 e 68,1\% não são ultrapassados por nenhuma amostra, indicando um processo estável.

FLORESTA, Curitiba, PR, v. 47, n. 2, p. 213 - 220, abr. / jun. 2017. 
A possível influência do teor de umidade inicial, que varia ao longo do ano para madeira de Pinus taeda segundo Brand et al. (2012), não foi observada no fornecimento de cavacos às empresas consumidoras. Da mesma forma, uma possível secagem mais rápida no final do período considerado, pelo aumento da temperatura média, também não foi observada. Merece consideração o fato que as cartas de controle apresentadas apenas detectam pequenas variações no processo após um considerável número de amostras.

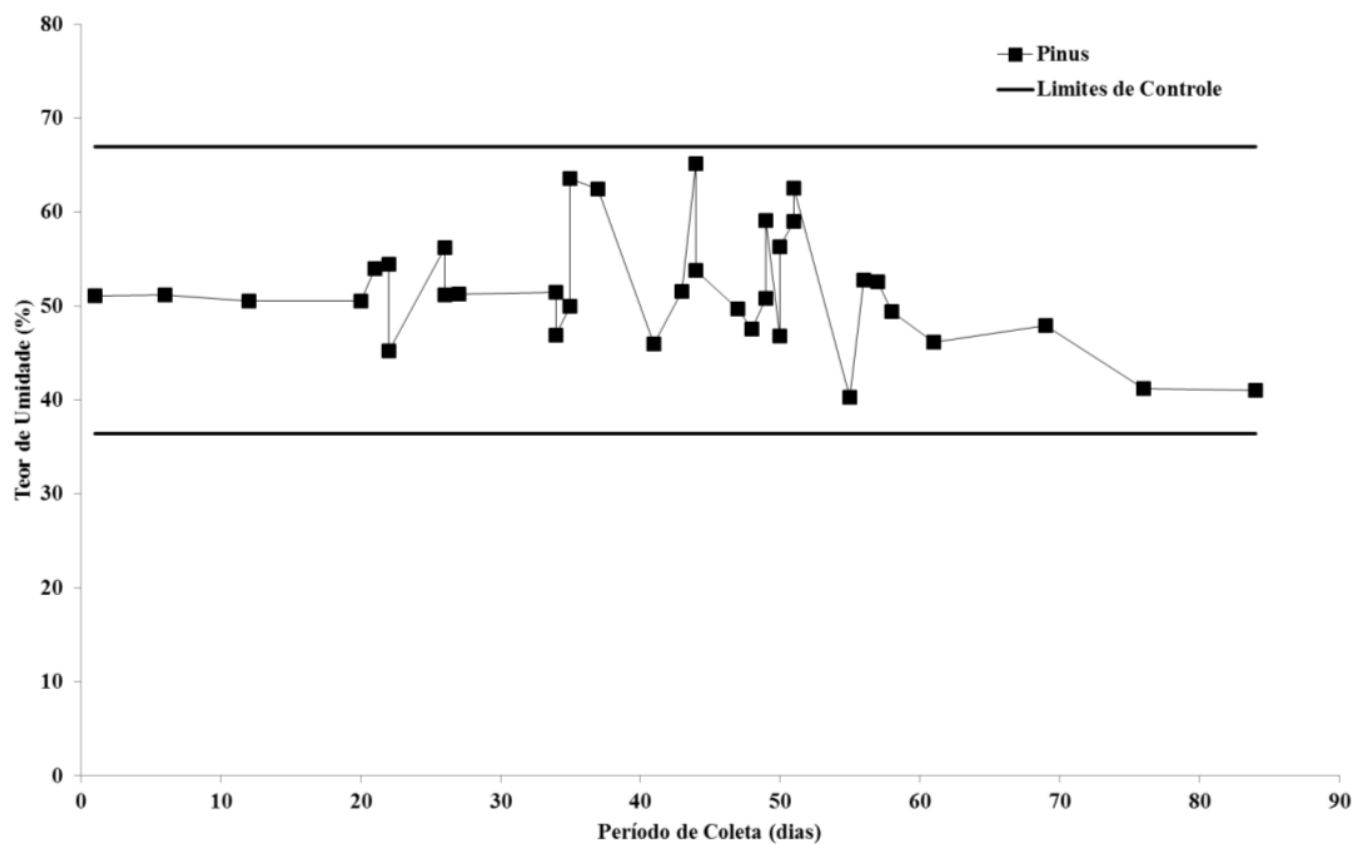

Figura 1. Teor de umidade dos cavacos de Pinus sp. ao longo do tempo e limites de controle para um processo estável.

Figure 1. Pinus sp. chips moisture content along the time and limits of control for a stable process.

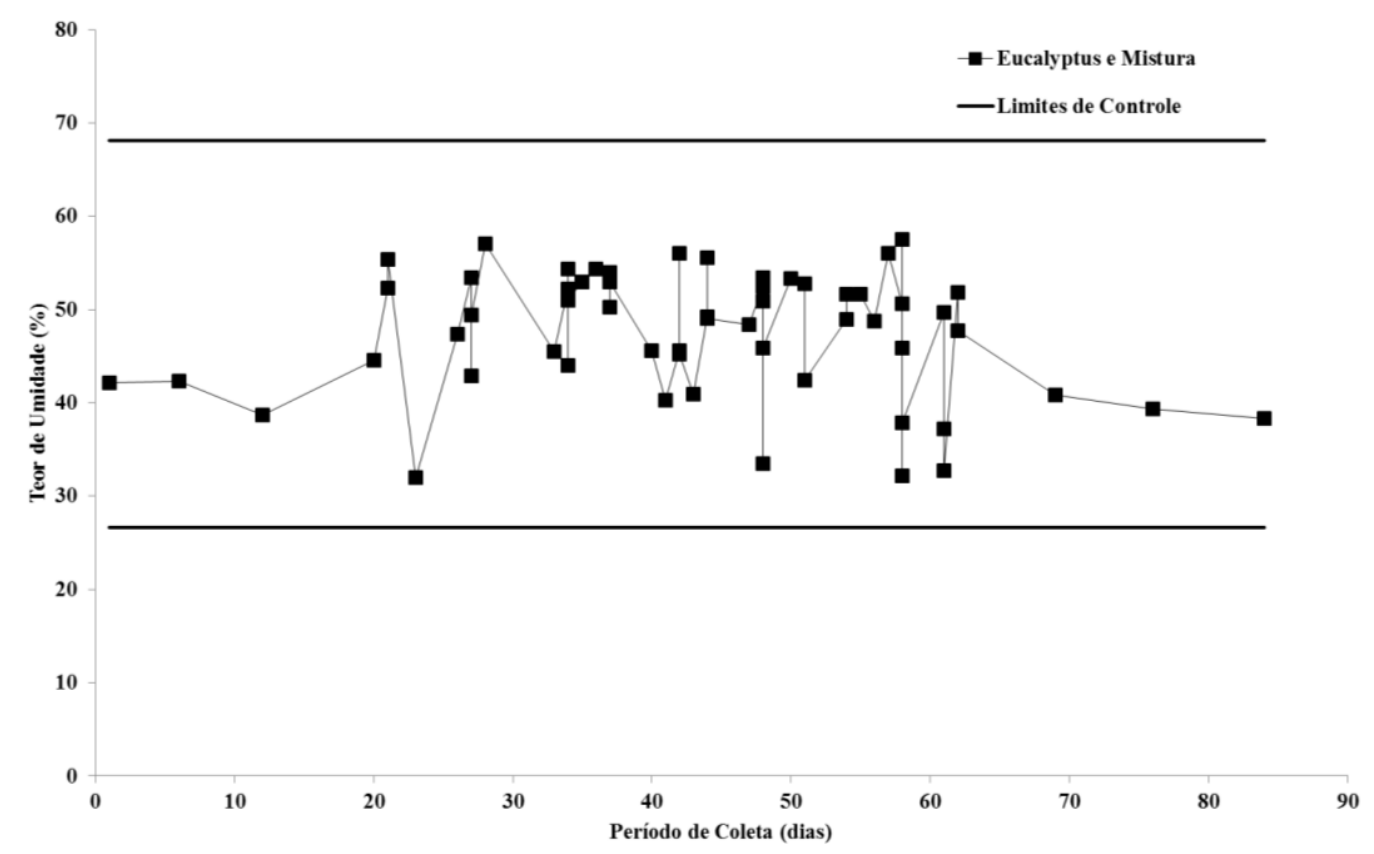

Figura 2. Teor de umidade dos cavacos de Eucalyptus sp. e misturas ao longo do tempo e limites de controle para um processo estável.

Figure 2. Eucalyptus sp. and mixture chips moisture content along the time and limits of control for a stable process. 
A competitividade da biomassa florestal certamente é prejudicada pelas características levantadas neste trabalho, de alto teor de umidade e de baixa massa específica, especialmente massa anidra por volume à granel. Apesar de haver diferenças significativas no teor de umidade e na massa específica dos cavacos, a comercialização pelo volume aparente ou pela massa úmida não estimula o fornecimento de material que tenha passado pela secagem. A hipótese de teor de umidade dos cavacos próximo ao inicial é confirmada especialmente para biomassa de Pinus sp. na forma de toretes.

\section{CONCLUSÕES}

- O teor de umidade da biomassa florestal, independente da espécie e da forma de apresentação é alto, próximo ao referenciado para árvores recém abatidas, resultado da ausência de ações para melhorar a qualidade como a secagem.

- Biomassa de Pinus sp. apresenta teor de umidade maior que a biomassa de Eucalyptus sp., especialmente na forma de toretes, possivelmente influenciada pela menor massa específica e pela ação impermeabilizante da casca.

- A massa específica à granel aparente e anidra dos cavacos de Pinus sp. é superior à dos cavacos de Eucalyptus, resultado do maior grau de compactação.

\section{REFERÊNCIAS}

ASTM INTERNATIONAL. D4442-07: Standard Test Methods for Direct Moisture Content Measurement of Wood and WoodBase Materials. West Conshohocken: Astm, 2007. 6 p.

BAKER, S. A.; GREENE, W. D.; WILSON, A. Fuels characteristics of woods-run whole tree southern pine chips. Biomass and Bioenergy, v. 37, p. 67-72, 2012.

BRAND, M. A.; BRITO, J. O.; QUIRINO, W. F.; MUÑIZ, G. I. B. de Influência da época de estocagem na qualidade da biomassa florestal para a geração de energia. Floresta, v. 42, n. 2, p. 369-380, 2012.

BRAND, M. A.; STÄHELIN, T. S. F.; FERREIRA, J. C.; NEVES, M. D. Produção de biomassa para geração de energia em povoamentos de Pinus taeda L. com diferentes idades. Árvore, v. 38, n. 2, p. 353-360, $2014 \mathrm{a}$.

BRAND, M. A.; MUÑIZ, G. I. B. de; QUIRINO, W. F.; BRITO, J. O. Storage as a tool to improve wood fuel quality. Biomass and Bioenergy, v. 35, p. 2581-2588, 2011.

BRAND, M. A.; MUÑIZ, G. I. B. de; BRITO, J. O.; QUIRINO, W. F. Influência das dimensões da biomassa estocada de Pinus taeda L. e Eucalyptus dunnii Maiden na qualidade do combustível para geração de energia. Árvore, v. 38, n. 1, p. 175-183, 2014b.

BRASIL. EMPRESA DE PESQUISA ENERGÉTICA. Balanço Energético Nacional 2014: Ano base 2013. Rio de Janeiro: Epe, 2014. 292 p.

DEFO, M.; BRUNETTE, G. A log drying model and its application to the simulation of the impact of bark loss. Forest Products Journal, v. 56, n. 5, p. 71-77, 2006.

DEUTSCHES INSTITUT FÜR NORMUNG. DIN EN ISO 17225-1: Solid biofuels - fuel specifications and classes - Part 1: General requirements. Berlin: Beuth Verlag Gmbh, 2014. 64 p.

ERBER, G.; KANZIAN, C.; STAMPFER, K. Predicting moisture content in a pine logwood pile for energy purposes. Silva Fennica, v. 46, n. 4, p. 555-567, 2012.

FURTADO, T. S.; FERREIRA, J. C.; BRAND, M. A.; MUÑIZ, G. I. B. de; QUIRINO, W. F. Mapeamento da frequência de uso e características da biomassa florestal utilizada para geração de energia em Lages, SC. Ciência Florestal, v. 22, n. 4, p. 795-802, 2012.

GATTO, D. A.; SANTINI, E. J.; HASELEIN, C. R.; DURLO, M. A. Características da lenha produzida na região da Quarta Colônia de Imigração Italiana do Rio Grande do Sul. Ciência Florestal, v. 13, n. 2, p. 7-16, 2003.

HASELEIN, C. R.; LOPES, M. de C.; SANTINI, E. J.; LONGHI, S. J.; ROSSO, S.; FERNANDES, D. L. G., MENEZES, L. F. de. Características tecnológicas da madeira de árvores matrizes de Eucalyptus grandis. Ciência Florestal, v. 14, n. 2, p. 145-1455, 2004.

FLORESTA, Curitiba, PR, v. 47, n. 2, p. 213 - 220, abr. / jun. 2017. 
MANLY, B. F. Exponential data transformation. The Statistician, v. 25, p. 37-42, 1976.

MUÑOZ, F.; MOYA, R. Moisture content variability in kiln-dried Gmelina arborea wood: effect of radial position and anatomical features. Journal Of Wood Science, v. 54, p. 318-322, 2008.

PANG, S.; XU, Q. Drying of woody biomass for bioenergy using packed moving bed dryer: mathematical modeling and optimization. Drying Technology, v. 28, n. 5, p. 702-709, 13 maio 2010. Informa UK Limited. DOI: $10.1080 / 07373931003799251$.

PARI, L.; CIVITARESE; GIUDICE, A del; ASSIRELLI, A.; SPINELLI, R.; SANTANGELO, E. Influence of chipping device and storage method on the quality of SRC poplar biomass. Biomass And Bioenergy, v. 51, p. 169-176, 2013.

PASILA, A. Changes, challenges and opportunities in the wood energy supply chain. Agronomy Research, v. 11, n. 2, p. 529-532, 2013.

PHANPHANICH, M.; MANI, S. Drying characteristics of pine forest residues. Bioresources, v. 5, n. 1, p. 108121,2009

RÖSER, D.; MOLA-YUDEGO, B.; SIKANEN, L.; PRINZ, R.; GRITTEN, D.; EMER; B.; VÄÄTÄINEN, K.; ERKKILÄ, A. Natural drying treatments during seasonal storage of wood for bioenergy in different European locations. Biomass and Bioenergy, v. 35, p. 4238-4247, 2011.

SANTOS, G. R. V.; JANKOWSKY, I. P.; ANDRADE, A. Curva característica de secagem para madeira de Eucalyptus grandis. Scientia Forestalis, v. 63, p. 214-220, 2003.

SENELWA, K.; SIMS, R. E. H. Fuel characteristics of short rotation forest biomass. Biomass and Bioenergy, v. 17, p. 127-140, 1999.

SOSA, A.; ACUNA, M.; MCDONNELL, K.; DEVLIN, G. Controlling moisture content and truck configurations to model and optimize biomass supply chain logistics in Ireland. Applied Energy, v. 137, p. 338$351,2015$.

SPINELLI, R.; NATI, C.; SOZZI, L.; MAGAGNOTTI, N.; PICCHI, G. Physical characterization of commercial woodchips on the Italian energy market. Fuel, v. 90, p. 2198-2202, 2011.

TENORIO, C.; MOYA, R.; CUBERO, R. Difusión del agua en astillas de madera de diez especies de rápido crecimiento en plantaciones en Costa Rica. Interciencia, v. 39, n. 2, p. 129-135, 2014.

VISSER, R.; BERKETT, H.; SPINELLI, R. Determining the effect of storage conditions on the natural drying of radiata pine logs for energy use. New Zealand Journal of Forestry Science, v. 44, n. 3, p. 1-8, 2014. 